\title{
Algoritmo Semiautomático para Mapear Incendios Forestales y Estimar la Recuperación Vegetal Mediante Imágenes Landsat-8
}

\section{Semi-Automatic Algorithm to Map Forest Fires and Estimate Vegetation Recovery Using Landsat-8 Images}

\author{
Jonathan Zhiminaicela Cabrera \\ Universidad Técnica de Machala \\ Machala, Ecuador \\ jzhiminai1@utmachala.edu.ec \\ Orcid: 0000-0001-9462-9608
}

\author{
José Quevedo Guerrero \\ Universidad Técnica de Machala \\ Machala, Ecuador \\ jquevedo@utmachala.edu.ec \\ Orcid: 0000-0002-8974-5628

\section{Cristhel Mora Encalada} \\ Universidad Técnica de Machala \\ Machala, Ecuador \\ cmora9@utmachala.edu.ec \\ Orcid: 0000-0002-0270-0962
}

\author{
María Belén León Salto \\ Universidad Yachay Tech \\ Urcuquí, Ecuador \\ maria.leon@yachaytech.edu.ec \\ Orcid: 0000-0001-8782-4261
}

\begin{abstract}
Resumen - Este estudio propone una metodología reproducible para la identificación, semi automática, de grandes incendios forestales y la estimación de la recuperación vegetal mediante el uso de imágenes satelitales Landsat 8 (OLI), y el análisis de la información obtenida del cálculo de índices espectrales. Para ello se desarrolló un algoritmo utilizando información de servidores de geo información y paquetes de análisis espacial del software R. Las imágenes satelitales procesadas se obtuvieron de la plataforma EarthExplorer del Servicio Geológico de Estados Unidos (USGS): antes, durante y después del incendio forestal producido en el Cantón Quilanga, Loja-Ecuador en el año 2019. Para ello, se realizó el cálculo de índices espectrales con el cual se procedió a identificar los índices de mejor aplicabilidad, por medio de un análisis visual, y una prueba de correlación de Pearson con un intervalo de confianza al 95\%, que corroboró el análisis visual. De ellos se obtuvo mejor correlación con referencia al índice normalizado de área quemada (NBRI). De acuerdo con los resultados obtenidos, se pudo delimitar el área afectada y estimar una recuperación temprana de la vegetación, pero no se pudo identificar las especies recuperadas.
\end{abstract}

Palabras Clave: Algoritmo R, índices espectrales, incendios forestales, imágenes satelitales, Landsat.
Abstract - This study proposes a reproducible methodology for the semi-automatic identification of large forest fires and the estimation of plant recovery using Landsat 8 (OLI) satellite images, and the analysis of information obtained from the calculation of spectral indices. For this purpose, an algorithm was developed using information from geo-information servers and spatial analysis packages from the $\mathrm{R}$ software. The processed satellite images were obtained from the EarthExplorer platform of the United States Geological Survey (USGS) before, during and after the forest fire in Quilanga, Loja-Ecuador in 2019. For this purpose, the calculation of spectral indices was carried out. Those spectral indices were employed to identify the indices of best applicability by means of a visual analysis and a Pearson correlation test with a $95 \%$ confidence interval, corroborating the visual analysis. The best correlation with reference to the NBRI was obtained. According to the results, it was possible to delimit the affected area and estimate the early recovery of the vegetation, however, it was not possible to identify the recovered species.

Keywords: R-algorithm, spectral indices, fires forest, satellite images, Landsat.

Sumario: I Introducción, II Resultados y Discusión, III Conclusiones.

Como citar: Zhiminaicela, Jonathan., Quevedo, José., León, María., \& Mora, Cristhel. (2020). Algoritmo Semiautomático para Mapear Incendios Forestales y Estimar la Recuperación Vegetal Mediante Imágenes Landsat8. Revista Tecnológica - Espol, 32(2). Recuperado a partir de http://www.rte.espol.edu.ec/index.php/tecnologica/article/view/757 


\section{INTRODUCCIÓN}

A nivel mundial la estación seca o verano propicia las condiciones atmosféricas idóneas para la propagación de incendios forestales, la cual genera problemas sociales, económicos y ambientales [1]. Ecuador no está exento de estos impactos. La temperatura promedio de Ecuador se encuentra entre $23-26{ }^{\circ} \mathrm{C}$; sin embargo, la temperatura máxima absoluta en aproximadamente el $30,12 \%$ del territorio ecuatoriano puede alcanzar los $32-34^{\circ} \mathrm{C}$ [2], con tendencias en su crecimiento, debido a la influencia que produce el cambio climático [3] y con diversas variaciones [4]. El índice de peligro de incendios forestales es directamente proporcional a la temperatura, por lo que estos cambios abruptos pueden implicar un gran potencial para la ocurrencia o propagación de los incendios forestales [1]. Así, la evaluación de los daños producidos y estimación del área de recuperación son de vital importancia para proponer medidas de mitigación y evitar la reincidencia en las áreas afectadas. Debido a que las áreas destruidas por incendios forestales son extensas, la evaluación in situ sería muy compleja. Una alternativa confiable y económica para la evaluación de los daños producidos son los Sistemas de Información Geográfica (SIG) y la teledetección [5].

Los incendios forestales se relacionan con el principio básico de combustión en el cual la temperatura y el cambio climático influyen directamente en el desarrollo de un incendio. Éstos se presentan con mayor frecuencia en la estación seca o verano, puesto que las variables climáticas son idóneas para la proliferación de un incendio, generando grandes pérdidas para la biodiversidad de una región [6]. Anualmente, la biodiversidad de los bosques forestales y la cobertura vegetal, principal regulador climático del Ecuador está siendo reducida como consecuencia de la recurrencia de los incendios forestales [1], especialmente en la región Andina, generando así la pérdida de extensas hectáreas de bosques.

Según la Secretaría del Convenio sobre la Diversidad Biológica (2010), las áreas afectadas por los incendios forestales producen un desorden en la fluctuación de las lluvias en esas zonas, provocando sequías que favorecen la susceptibilidad a un futuro incendio; por ende, se necesita estimar la afectación y recuperación del área para plantear medidas de restauración y ayudar a regulación en la incidencia.

Los estudios para determinar las áreas afectadas por incendios forestales, utilizando imágenes satelitales Landsat 8 [7], han demostrado tener valores bajos en el error por omisión, debido a la resolución espacial de las bandas espectrales generadas por los sensores de los satélites, los cuales permiten tener una visión más clara del efecto producido al territorio [7]. No obstante, al comparar el uso de imágenes de los satélites Landsat 8 y Sentinel-2 se evidenció menor tasa de error por omisión en Sentinel 2 , cuya aplicación es aceptable puesto que contiene rangos de similitud [8] y error por omisión [9], o en otras imágenes como WorldView-2, imágenes con mayor resolución espacial [10]. Aunque a medida que aumenta el área afectada por incendios, los errores de omisión disminuyen [11]. Además, se complementan con el cálculo de los diversos índices espectrales con imágenes Landsat 7 y Landsat 8 [12].
Adicionar una clasificación semi supervisada permitiría la reducción los errores de bandas espectrales, pues en general el error se asocia a delimitaciones del área [9]. Pese a que se han realizado múltiples estudios no es posible deducir con exactitud o aseverar el efecto producido por los incendios. Las inferencias obtenidas permiten estimar el área global de afectación; consecuentemente, es una herramienta que contribuye a la toma de decisiones adecuadas acorde a la visión general del área afectada [13]. Esto se debe a que cada incendio debe ser tomado en cuenta para la valoración con diversas variables, tales como el área de quemado, las condiciones topográficas [14], la nubosidad y otras. Generalmente se utiliza la clasificación supervisada, ya que permite obtener resultados más confiables [15]. En caso de falencias de información o inversión, una técnica ideal para reducir errores es la clasificación semi supervisada. Existen diversos índices espectrales que utilizan imágenes satelitales para el cálculo del área abrasada. Regularmente se utilizan las imágenes del satélite Sentinel 2, implementadas con índices espectrales que evalúa el estado de la vegetación [16], los que permiten el mapeo y clasificación de la cobertura vegetal por medio del uso de bandas espectrales [7]. Sin embargo, la mayoría de estos estudios se limitan al uso y análisis de un índice espectral. En base a los antecedentes mencionados y a la nula o escasa aplicación de estas herramientas, en Ecuador se propone emplear RStoolbox, un paquete del software $\mathrm{R}$, para analizar y comparar índices espectrales de las imágenes tele detectadas [11], permitiendo así identificar el índice adecuado para mapear el área de quemado; además, se pretende acoplar las correcciones radiométricas y de reflectancia con el paquete Landsat 8 [17].

\section{A. Área de estudio}

Para el análisis se consideró al incendio forestal más grande que ocurrió en Ecuador, con el cual se puede evitar los errores por omisión, pues a mayor extensión de incendio se presenta menor cantidad de errores por omisión [9]. El área de estudio evaluada se ubica en el cantón Quilanga, Loja al Sur del Ecuador. Véase en la Fig. 1
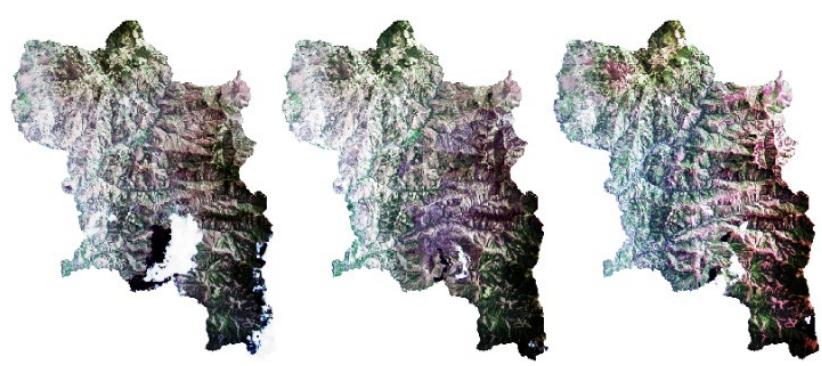

Fig. 1 Imagen del cantón Quilanga imagen RGB de Landsat 8

En esta zona, las condiciones topográficas, estación climática y las condiciones atmosféricas tales como el viento, favorecen la proliferación de un incendio. De acuerdo a los reportes del INAHMI, en esta región los vientos pueden alcanzar hasta $8 \mathrm{~m} / \mathrm{s}$ [18]. Las zonas forestales y las especies endémicas recientemente identificadas son las más afectadas y degradadas debido a diversos factores antropológicos que promueven su degradación [19]. 


\section{B. Imágenes satelitales}

Se utilizaron imágenes satelitales Landsat 8 OLI tomadas antes, durante y después del incendio forestal, lo más próximo al cierre de esta investigación. Descrito en la TABLA I, en el PATH= 10 y ROW 63. Estas imágenes fueron obtenidas del servidor USGS.

TABLA I

IMÁGENES UTILIZADAS EN EL ESTUDIO

\begin{tabular}{|c|c|c|}
\hline \multirow{2}{*}{ Tiempo } & Imágenes satelitales Landsat 8 (OLI) \\
\cline { 2 - 3 } & Identificador-producto & Fecha \\
\hline \multirow{2}{*}{ Antes } & LC08_L1TP_010063_20190825_20190903_01 & $25 / 08 / 2019$ \\
\hline \multirow{2}{*}{ Durante } & LC08_L1TP_010063_20190926_20191017_01 & $26 / 09 / 2019$ \\
\hline Después & LC08_L1TP_010063_20200421_20200508_01 & 21/04/2020 \\
\hline
\end{tabular}

En este estudio se utilizaron imágenes Landsat 8 debido a la resolución espacial de sus bandas espectrales y los beneficios que estas brindan para el estudio [20]. Véase en la Fig. 2. Además, el manejo y procesamiento de estas imágenes no implican un gasto, por lo que su aplicación es económicamente rentable.

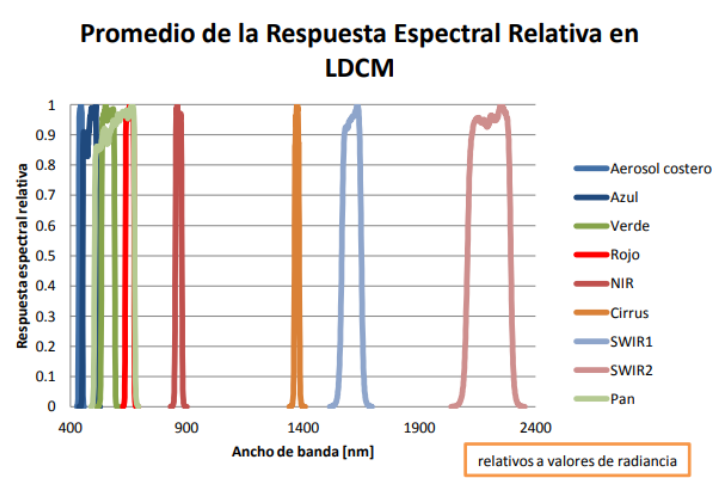

Fig. 2 Respuesta espectral LDCM

El proceso podría llevarse a cabo y obtener buenos resultados con imágenes Landsat 7 [21], lo que beneficiaría la aplicación del algoritmo presentado en este trabajo cuando se necesiten imágenes antepuestas al lanzamiento de Landsat 8 en 2013.

\section{Identificación del área de estudio.}

Para identificar el área de afectación se utilizó el software QGIS versión 3.12 de código abierto, empleando herramientas que permiten añadir capas tomando en cuenta la banda 5 después del incendio, imagen satelital de Landsat 8 OLI. Véase en la Fig. 3.

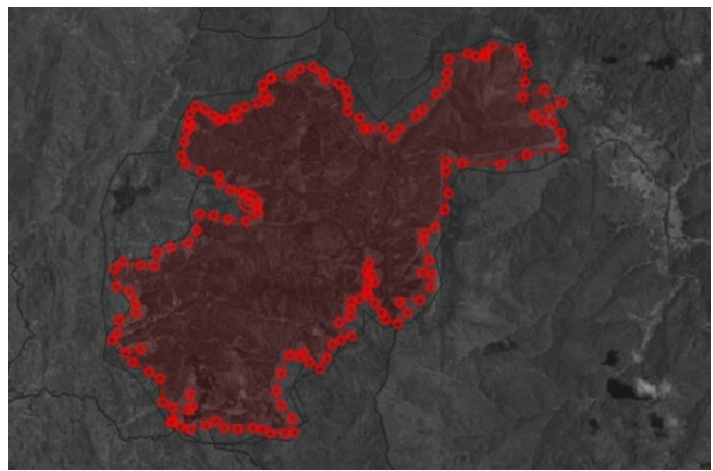

Fig. 3 Identificación de la expansión del incendio forestal

\section{Software R}

Para el estudio se utilizó el software $\mathrm{R}$ y como modulador el software RStudio. El sistema utilizado y sus herramientas de procesamiento facilitan la reproducción de las investigaciones [22].

\section{E. Índices espectrales}

El cálculo de índices espectrales permite conocer el estado de la cobertura vegetal, por ende, su aplicación en estudios para determinar las afectaciones producidas en la cobertura vegetal es pertinente [16]. Además, puede utilizarse para prever posibles incendios forestales [23]. El paquete RStoolbox del Software R, permite realizar el cálculo de más de veinte índices los cuales son descritos en su paquete de $\mathrm{R}$ [24]

\section{$F$. Descripción del algoritmo con los paquetes de $R$}

En este estudio se utilizó el software R y RStudio, herramientas informáticas individuales que permitieron mapear y estimar la recuperación del incendio forestal producido en Quilanga en 2019. El algoritmo se describe en la Fig. 4.

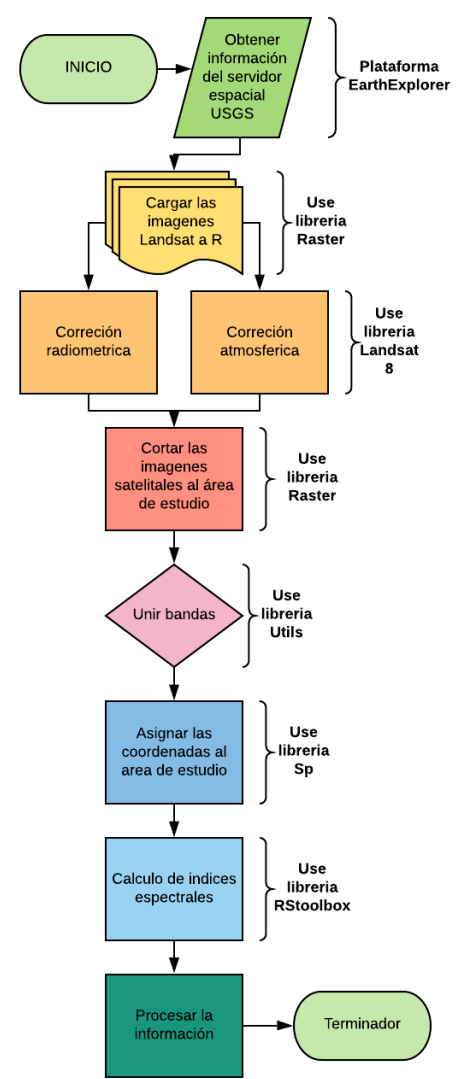

Fig. 4 Diagrama de flujo del algoritmo para el procesamiento de las imágenes satelitales Landsat 8

\section{G. Evaluación de la severidad}

Se debe conocer los rangos interespecíficos para reconocer la salud de la vegetación. Estos rangos pueden ser interpretados mediante el procesamiento de la información espectral incluida en la cartografía del área quemada [25].

\section{H. Evaluación de la recuperación}

Tanto las imágenes Landsat [26], como los índices espectrales [27] tienen diversas aplicaciones y cumplen 
diversas funciones. Para determinar los de mejor aplicabilidad, se realizó un análisis visual [28] de las gráficas obtenidas desde el cálculo de índices espectrales, y se hizo una prueba de correlación de Pearson [29] para corroborar estos resultados con un nivel de significancia del 95\% entre índices espectrales, tomando en cuenta el área donde ocurrió el incendio, cortada con la capa obtenida en QGIS, lo cual se observa en la Fig. 3; para ello se extrajeron los valores y se realizó una prueba de correlación con referencia al índice normalizado de área quemada (NBRI), siendo este índice el de mayor aplicación. Los resultados se presentan en la Fig. 5.

\section{RESULTADOS Y DISCUSIÓN}

De los índices espectrales obtenidos en el estudio para identificar los de mejor aplicabilidad, se determinó visualmente que el índice que permitió identificar con mayor precisión la severidad del incendio forestal fue NBRI. Siendo este índice representado en tres momentos en la antes en la Fig. 6, durante en la ¡Error! No se encuentra el origen de la referencia., después del incendio forestal en la Fig. 8, representándose imágenes del cantón Quilanga, donde se suscitó el incendio forestal más grande del Ecuador en el año 2019.

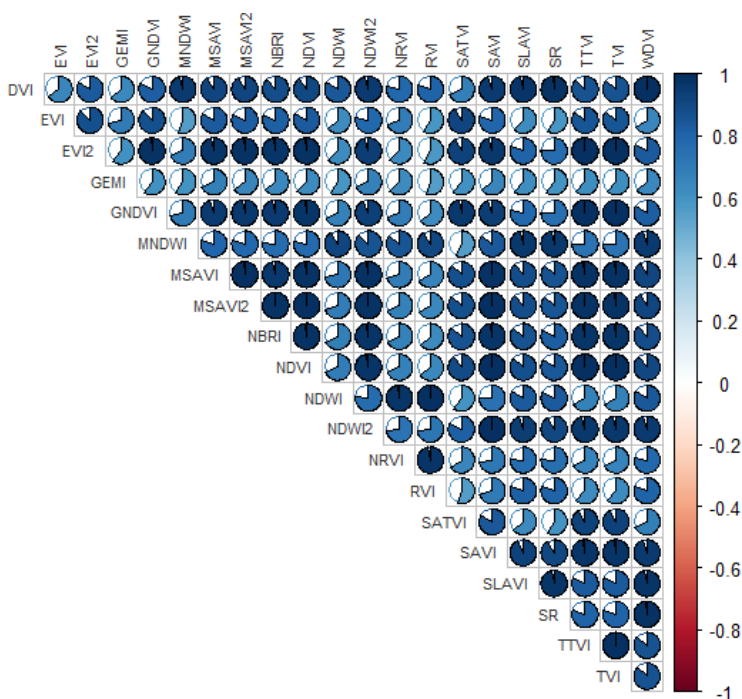

Fig. 5 Prueba de correlación de Pearson entre índices espectrales

De entre los índices seleccionados se consideró la aplicabilidad de acuerdo a la características e información que brindan los índices espectrales. Obteniendo así en los índices evaluados mejor correlación con referencia al índice de relación de quemado normalizado NBRI. El índice de vegetación ajustado al suelo $\mathrm{SAVI}=0.98$, índice de vegetación de diferencia normalizada verde GNDVI= 0.96, índice de vegetación mejorado de dos bandas EVI2= 0.97 , índice de vegetación de diferencia DVI $=0.89 \mathrm{y}$ índice de vegetación de diferencia normalizada NDVI= 0.98 .

\section{Severidad del incendio forestal NBRI}

1) Antes del Incendio forestal: Se puede identificar por medio de la imagen espectral en la Fig. 6; el cantón Quilanga pertenece a la zona andina, pero se encontraba en la estación seca. El valor promedio de NBRI es de 0.31, lo cual alude a una vegetación medianamente sana.

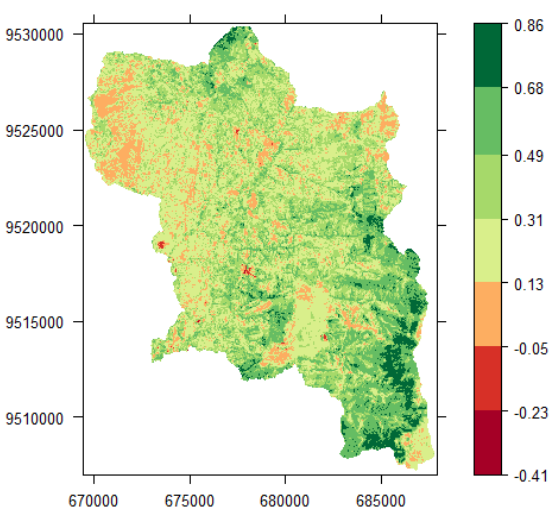

Fig. 6 Imagen espectral del cantón Quilanga antes del incendio forestal con el índice NBRI

2) Durante el incendio forestal: La fase presentada en la imagen espectral en la Fig. 7, presenta el momento más próximo al control del incendio forestal. Los daños se pueden observar con claridad y precisión las afectaciones.

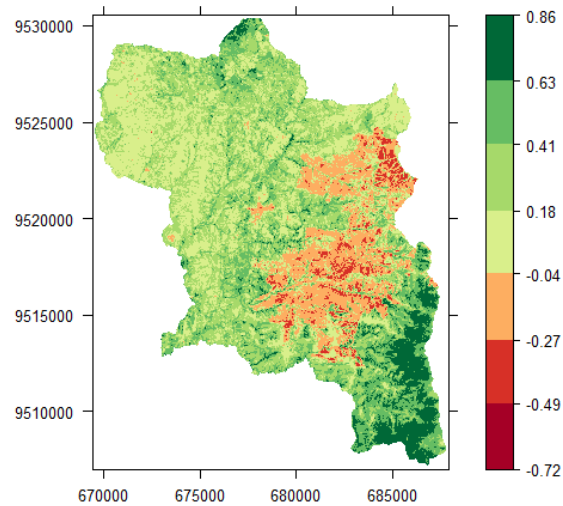

Fig. 7 Imagen espectral del cantón Quilanga durante el incendio forestal con el índice NBRI

3) Después del incendio forestal: Se observa una recuperación temprana de la vegetación con rangos promedio en el área afectada de 0.34 y en menor medida por debajo de 0.16. Véase la Fig. 8.

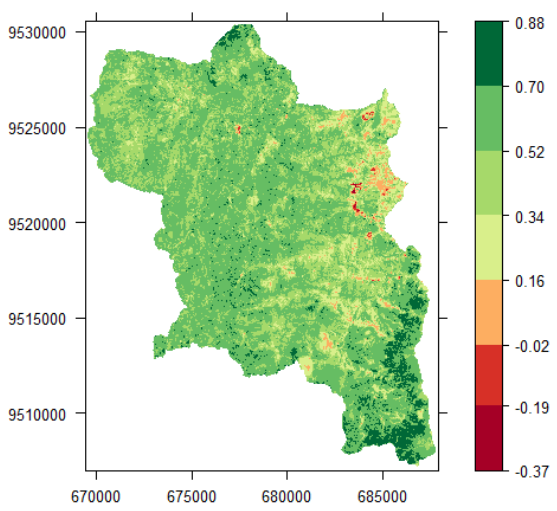

Fig. 8 Imagen espectral del cantón Quilanga después del incendio forestal con el índice NBRI

\section{J. Severidad del incendio forestal índices con similitud}

Adicional al índice NBRI, el paquete RStoolbox proporciona el cálculo de más de treinta índices espectrales, herramienta que permite elegir el índice de mejor aplicabilidad para el mapeo de incendios forestales, 
siendo éstos los índices: DVI, véase la Fig. 9; EVI2, véase la Fig. 10; GNDVI, véase en la Fig. 11, que, de acuerdo al análisis visual y la prueba de correlación.

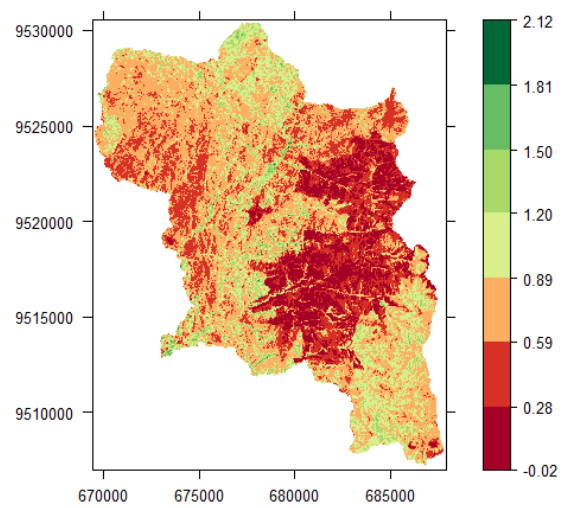

Fig. 9 Imagen espectral del cantón Quilanga índice DVI

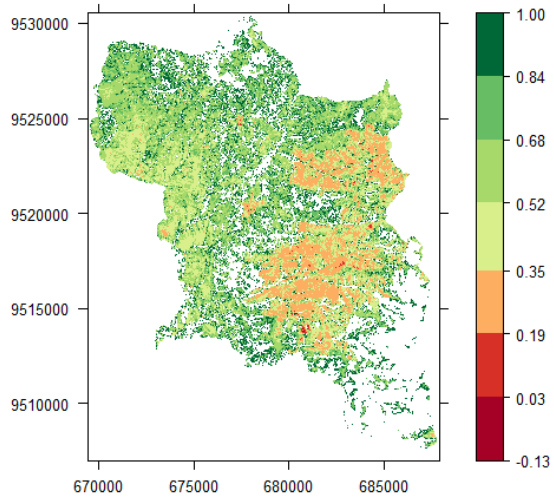

Fig. 10 Imagen espectral del cantón Quilanga índice EVI2

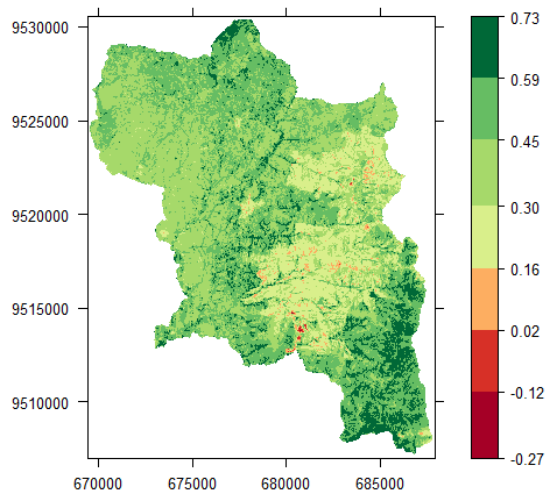

Fig. 11 Imagen espectral del cantón Quilanga índice GNDVI

Las imágenes satelitales Sentinel 2, las cuales tienen un valor monetario por unidad, son utilizadas generalmente para realizar mapeos de incendios forestales [30]. Es por esto que este estudio se efectuó con imágenes Landsat 8; adicionalmente se trabajó con el índice NDVI que mide la salud de la vegetación, por ende, permite mapear la cobertura vegetal. Es por esto que se consideró al NDVI como herramienta adecuada para estimar la recuperación vegetal [31].

\section{K. Mapeo de la recuperación de la vegetación afectada por el incendio forestal.}

Para mapear la recuperación de la cobertura vegetal se propusieron el índice NDVI, que se observa en la Fig. 12 y el índice SAVI, representado en la Fig. 13.

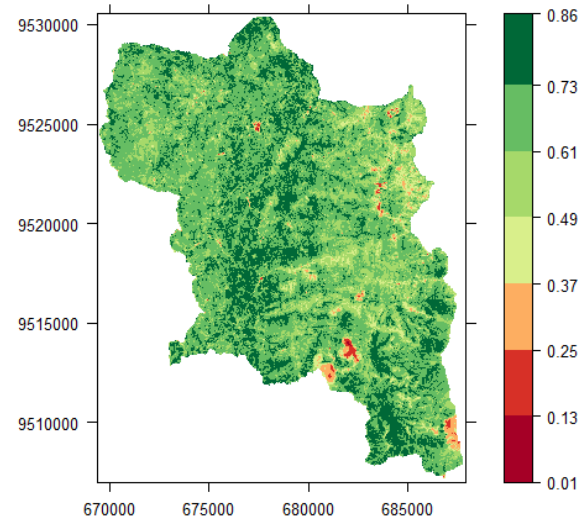

Fig. 12 Imagen espectral del cantón Quilanga índice NDVI

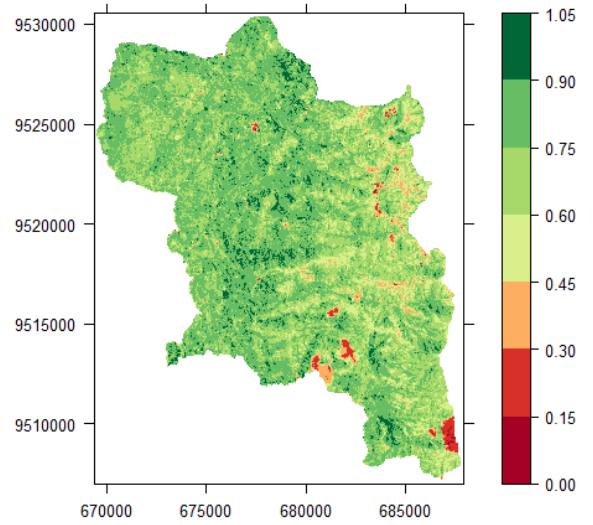

Fig. 13 Imagen espectral del cantón Quilanga índice SAVI

Los resultados obtenidos son aplicables en estudios espectrales para conocer el estado de la cobertura vegetal. Además pueden ser utilizados en la evaluación y análisis de factores externos al estudio como en agricultura de precisión [32].

\section{Estimación de la recuperación vegetal.}

Los resultados obtenidos se pueden contrastar con los valores promedio representados en la Fig. 14. En dicha infografía se expresan los valores espectrales de las diferentes fases, tales como: Antes, durante y después del incendio forestal. Generalmente, la presencia de valores espectrales negativos representa daños graves en la cobertura vegetal[16][27][23].

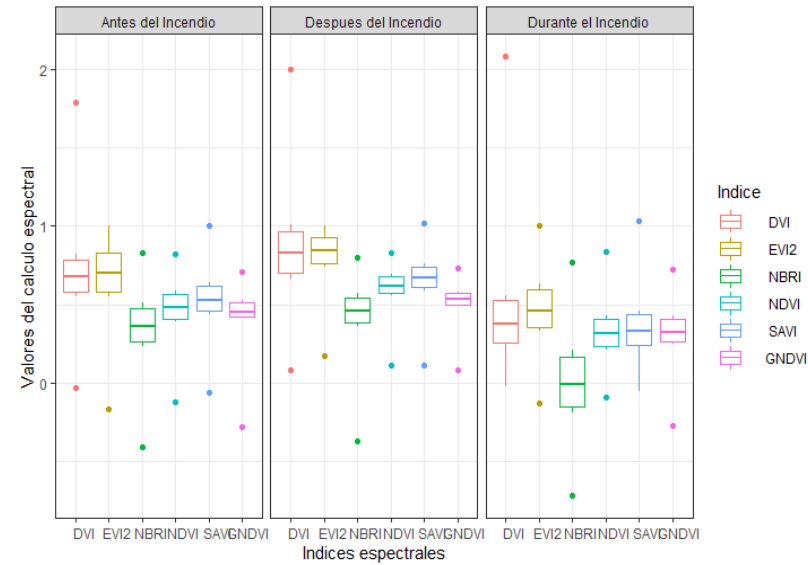

Fig. 14 Valores espectrales de las imágenes Landsat 8, en los tres tiempos de evaluación 
Los valores espectrales obtenidos en el estudio dos permiten conocer dos aspectos generales del comportamiento de la vegetación antes, durante y después del incendio:

1) El comportamiento de la vegetación y su recuperación: Los valores de los índices NDVI fueron: antes -0.12 a 0.46 con tendencia positiva, durante -0.09 a 0.47 con tendencia negativa y después $0.01 ; 0.47$. Este comportamiento se repite en el índice SAVI representado en el diagrama de cajas de la Fig. 14. Estos valores permiten inferir que hubo una recuperación vegetativa de acuerdo al análisis espectral [33][10][9][15][29], pero no se pudo identificar el tipo de vegetación recuperada, puesto que el cálculo de índices espectrales permite hacer estimaciones como otras herramientas que utilizan teledetección. De acuerdo al resultado obtenido y los valores espectrales se puede aseverar que hubo una recuperación temprana de la cobertura vegetal.

2) Mapeo del incendio forestal: Para identificar y mapear los incendios forestales se utilizó como referencia el índice NBRI siendo este el de mayor aplicación y una prueba de correlación de Pearson para con los demás índices espectrales obteniendo, así en los índices evaluados mejor correlación con referencia al NBRI. El índice SAVI= 0.98 , el GNDVI $=0.96, \mathrm{EVI} 2=0.97, \mathrm{DVI}=0.89$ y $\mathrm{NDVI}=$ 0.98. Además, visualmente se puede constatar estos resultados en las Fig. 7, Fig. 9, Fig. 10, Fig. 11, Fig. 12 y Fig. 13.

\section{CONCLUSIONES}

En Ecuador las imágenes satelitales han sido utilizadas para evaluar el estado de los cultivos y relacionarlos con su rendimiento [34]. Sin embargo, estos procesos de tratamiento y análisis de imágenes satelitales no se han aplicado a otros campos. Debido al gran impacto económico, ambiental y social negativo que producen los incendios forestales anualmente al país, se debería considerar la aplicación de estos estudios.

El algoritmo presentado en esta investigación permite evaluar el área afectada y así obtener una visión general de los daños ocasionados por este tipo de desastres, lo cual lo convierte en una herramienta de fácil aplicabilidad y reproducción. Este algoritmo se complementa mediante el uso de imágenes satelitales Landsat 8 y el software R. El software $\mathrm{R}$ facilita la reproducción de este estudio, debido a que la plataforma facilita la utilización de versiones anteriores, por esta razón las actualizaciones que se realicen no limitan su efectividad.

Asimismo, el software R permite tener una visión clara y global en el mapeo de incendios forestales, especialmente la delimitación del mismo. La aplicación del algoritmo en $\mathrm{R}$ facilita la obtención de imágenes de alta calidad y una visión de la afectación en áreas, por lo cual el algoritmo puede ser aplicado con enfoques para la evaluación de cultivos, pues la facilidad del package RStoolbox y el software $\mathrm{R}$, permiten la facilidad de tener una gama de índices espectrales con múltiples aplicaciones.

En el análisis post incendio, se puede deducir una temprana recuperación a nivel espectral de la vegetación, la cual se puede ver influenciada en la fecha que se adquirió la imagen post incendio, en el mes de abril, donde hay mayor fluctuación de la precipitación. Pero a nivel general, debido a que es una herramienta de estimación, se pudo cumplir con los objetivos planteados, sin la necesidad generar los costos que in situ se producen al estudiarlos o al realizar una clasificación supervisada.

Todos los estudios a nivel espectral con imágenes satelitales nos permiten hacer estimaciones, pero no se puede conocer con exacta certeza lo que sucede en campo. Esta herramienta es una alternativa para realizar monitoreo e identificar donde es necesario realizar oportunamente medidas de biorremediación.

Este estudio ayuda abrir un mayor desarrollo en la investigación en estos campos de la teledetección de incendios forestales, pues su facilidad de replicación le dará un aporte favorable al uso de herramientas convencionales, donde se debe tener mayor campo de conocimiento. Se debe considerar, antes de realizar el estudio, factores como nubosidad, facilidad para interpretar los valores espectrales, conocimientos medios en el manejo del software $\mathrm{R}$ y la identificación del área afectada.

\section{RECONOCIMIENTOS}

Este trabajo ha sido financiado parcialmente por el Proyecto de Investigación del Mapeo de Grandes Incendios Forestales de Ecuador, del Semillero de Investigación en Recursos Fitogéneticos de la Universidad Técnica de Machala (SIRF/UTMACH).

Los autores desean expresar su agradecimiento a Angel Eduardo Luna Romero, MSc, quien dicta la materia de Geomática en la Facultad de Ciencias Agropecuarias de la UTMACH, por motivar a sus estudiantes al desarrollo de investigaciones, a MIND Research Group (https://mindresearchgroup.com/) por promover y apoyar a sus miembros en el proceso de investigación.

\section{REFERENCIAS}

[1] D. Pazmiño, "Peligro de incendios forestales asociado a factores climáticos en Ecuador" FIGEMPA Investig y Desarro, vol. 1 no. 1, pp. 10-18, Jun. 2019, doi: 10.29166/revfig.v1i1.1800.

[2] J. G. Barros López and A. Y. Troncoso Salgado, "Atlas climatológico del Ecuador,” Escuela Politecnica Nacional, 2010.

[3] S. A. Vega Aguilar, C. C. Malla Ceferino, and H. F. Bejarano Copo, "Evidencias del cambio climático en Ecuador," Rev. Agroecosistemas, vol. 8, no. 1, pp. 72-76, 2020.

[4] F. Navarro-Serrano et al., "Maximum and minimum air temperature lapse rates in the Andean region of Ecuador and Peru," Int. J. Climatol., p. joc.6574, Apr. 2020, doi: 10.1002/joc.6574.

[5] E. Chuvieco, I. Aguado, J. Salas, M. García, M. Yebra, and P. Oliva, "Satellite Remote Sensing Contributions to Wildland Fire Science and Management," Curr. For. Reports, vol. 6, no. 2, pp. 81-96, Jun. 2020, doi: 10.1007/s40725-020-00116-5.

[6] M. . Flannigan, B. . Stocks, and B. . Wotton, "Climate change and forest fires," Sci. Total Environ., vol. 262, no. 3, pp. 221-229, Nov. 2000, doi: 10.1016/S0048-9697(00)00524-6.

[7] W. Schroeder, P. Oliva, L. Giglio, B. Quayle, E. Lorenz, and F. Morelli, "Active fire detection using Landsat-8/OLI data," Remote Sens. Environ., vol. 185, pp. 210-220, Nov. 2016, doi: 10.1016/j.rse.2015.08.032.

[8] J. Delegido et al., "Estimación del grado de severidad de incendios en el sur de la provincia de Buenos Aires, Argentina, usando Sentinel-2 y su comparación con Landsat-8," Rev. Teledetección, no. 51, p. 47, Jun. 2018, doi: 10.4995/raet.2018.8934.

[9] U. A. Bezzera, L. M. M. Oliveira, A. L. B. Candeias, B. B. Silva, A. C. L. S. Leite, and L. T. M. S. Silva, "Comparison of the Normalized Difference Vegetation Index (NDVI) Between the 
Sensors OLI-Landsat Satellite-8 and MSI-Sentinel-2 Satellite in Semi-Arid Region," Anuário do Inst. Geociências - UFRJ, vol. 41, no. 3, pp. 167-177, Dec. 2018, doi: 10.11137/2018 3167177.

[10] Z. Wu, B. Middleton, R. Hetzler, J. Vogel, and D. Dye, "Vegetation Burn Severity Mapping Using Landsat- 8 and WorldView-2," Photogramm. Eng. Remote Sens., vol. 81, no. 2, pp. 143-154, Feb. 2015, doi: 10.14358/PERS.81.2.143.

[11] F. Li, X. Zhang, S. Kondragunta, C. C. Schmidt, and C. D. Holmes, "A preliminary evaluation of GOES-16 active fire product using Landsat- 8 and VIIRS active fire data, and ground-based prescribed fire records," Remote Sens. Environ., vol. 237, p. 111600, Feb. 2020, doi: 10.1016/j.rse.2019.111600.

[12] P. Li, L. Jiang, and Z. Feng, "Cross-Comparison of Vegetation Indices Derived from Landsat-7 Enhanced Thematic Mapper Plus (ETM+) and Landsat-8 Operational Land Imager (OLI) Sensors,' Remote Sens., vol. 6, no. 1, pp. 310-329, Dec. 2013, doi: 10.3390/rs6010310.

[13] C. K. Brewer, J. C. Winne, R. L. Redmond, D. W. Opitz, and M. V. Mangrich, "Classifying and Mapping Wildfire Severity," Photogramm. Eng. Remote Sens., vol. 71, no. 11, pp. 1311-1320, Nov. 2005, doi: 10.14358/PERS.71.11.1311.

[14] R. W. Bussmann, "Bosques andinos del sur de Ecuador, clasificación, regeneración y uso.," Rev. Peru. Biol., vol. 12, no. 2, pp. 203-216, 2005

[15] E. Gómez-Sánchez, J. De las Heras, M. Lucas-Borja, and D. Moya, "Ajuste de metodologías para evaluar severidad de quemado en zonas semiáridas (SE peninsular): incendio Donceles 2012," Rev. Teledetección, no. 49, p. 103, Dec. 2017, doi: 10.4995/raet.2017.7121.

[16] M. A. Peña and J. Ulloa, "Mapeo de la recuperación de la vegetación quemada mediante la clasificación de índices espectrales pre- y post-incendio," Rev. Teledetección, no. 50, p. 37, Dec. 2017, doi: 10.4995/raet.2017.7931.

[17] S. C. Goslee, "Analyzing Remote Sensing Data in R: The landsat Package," J. Stat. Softw., vol. 43, no. 4, 2011, doi 10.18637/jss.v043.i04.

[18] J. Maldonado and L. Álvarez, O., Montaño, T Tenechagua, "Análisis Climático de la Velocidad del Viento en la Región Sur del Ecuador," Rev. Politécnica, vol. 35, no. 3, p. 137, 2015.

[19] G. Aguirre, Zhofre Mendoza. Geada-Lopez, "Estado de conservación de los bosques secos de la provincia de Loja, Ecuador," Arnaldoa, vol. 24, no. 1, Jun. 2017, doi: 10.22497/arnaldoa.241.24107.

[20] J. Barsi, K. Lee, G. Kvaran, B. Markham, and J. Pedelty, "The Spectral Response of the Landsat-8 Operational Land Imager," Remote Sens., vol. 6, no. 10, pp. 10232-10251, Oct. 2014, doi: 10.3390/rs61010232.

[21] A. R. López García, "Estudio de la severidad y regeneración de la vegetación por el incendio de 2012 en el Bosque La Primavera (México) mediante imágenes LANDSAT 7," Rev. Cart., no. 101, pp. 35-50, Jun. 2020, doi: 10.35424/rcarto.v0i101.420.

[22] C. Gandrud, Reproducible research with $R$ and $R$ studio. Taylor \& Francis Gropu, 2013

[23] P. Illera, A. Fernández, and J. A. Delgado, "Temporal evolution of the NDVI as an indicator of forest fire danger," Int. J. Remote Sens., vol. 17, no. 6, pp. 1093-1105, Apr. 1996, doi: 10.1080/01431169608949072.

[24] R. J. Leutner, B., Horning, N., Schwalb-Willmann, J., \& Hijmans, "RStoolbox: tools for remote sensing data analysis. R package version 0.1, 7." 2017.

[25] E. Bastarrika Izagirre, A. y Chuvieco Salinero, "Cartografía del área quemada mediante crecimiento de regiones: aplicación en entornos mediterráneos con imágenes tm y etm+1," GeoFocus, vol. 6, pp. 82-204, 2006.

[26] A. R. Montellano, "Cartografía multitemporal de quemas e incendios forestales en Bolivia: Detección y validación postincendio," Ecol. en Boliv., vol. 47, no. 1, pp. 53-71, 2012.

[27] S. Martínez, E. Chuvieco, I. Aguado, and J. Salas, "Burn severity and regeneration in large forest fires: an analysis from Landsat time series," Rev. Teledetección, no. 49, p. 17, Dec. 2017, doi: 10.4995/raet.2017.7182.

[28] C. Gómez et al., "Cartografía anual de incendios forestales (19852015) en el Noroeste de España a partir de serie temporal de datos Landsat y algoritmo Composite2Change," in Nuevas plataformas y sensores de teledetección. XVII Congreso de la Asociación Española de Teledetección, 2017, pp. 169-172.

[29] A. Collingwood, P. Treitz, F. Charbonneau, and D. Atkinson,
"Artificial Neural Network Modeling of High Arctic Phytomass Using Synthetic Aperture Radar and Multispectral Data," Remote Sens., vol. 6, no. 3, pp. 2134-2153, Mar. 2014, doi: $10.3390 / \mathrm{rs} 6032134$

[30] A. Fernández-Manso, O. Fernández-Manso, and C. Quintano, "SENTINEL-2A red-edge spectral indices suitability for discriminating burn severity," Int. J. Appl. Earth Obs. Geoinf., vol. 50, pp. 170-175, Aug. 2016, doi: 10.1016/j.jag.2016.03.005.

[31] P. Teillet, "Effects of spectral, spatial, and radiometric characteristics on remote sensing vegetation indices of forested regions," Remote Sens. Environ., vol. 61, no. 1, pp. 139-149, Jul. 1997, doi: 10.1016/S0034-4257(96)00248-9.

[32] S. Kharuf-Gutierrez, R. Orozco-Morales, O. de la C. Aday Díaz, and E. Pineda Ruiz, "Multispectral aerial image processing system for precision agriculture," Sist. y Telemática, vol. 16, no. 47, Oct. 2018, doi: 10.18046/syt.v16i47.3221.

[33] S. Pesaresi, A. Mancini, G. Quattrini, and S. Casavecchia, "Mapping Mediterranean Forest Plant Associations and Habitats with Functional Principal Component Analysis Using Landsat 8 NDVI Time Series," Remote Sens., vol. 12, no. 7, p. 1132, Apr. 2020, doi: $10.3390 /$ rs 12071132 .

[34] C. G. Aguilar, "Aplicación de índices de vegetación derivados de imágenes satelitales para análisis de coberturas vegetales en la provincia de Loja, Ecuador.," CEDAMAZ, vol. 5, no. 1, pp. 30-41, 2015 . 